\title{
Ex-post Enforcement in Spectrum Sharing
}

\author{
Amer S. Malki \\ Email: asm110@pitt.edu \\ School of Information Sciences \\ University of Pittsburgh \\ Pittsburgh PA
}

\author{
Martin BH Weiss \\ Email:mbw@pitt.edu \\ School of Information Sciences \\ University of Pittsburgh \\ Pittsburgh PA
}

\begin{abstract}
Spectrum sharing is emerging as a key strategy for future wireless communications systems. Enforcement is a requirement for spectrum sharing to protect the incumbent of the spectrum from bad interference. Practical schemes have linked together ex-ante and ex-post enforcement. The design of the overall enforcement system may give more emphasis to one or the other. The emphasis in commercial-government sharing in the United States has been on ex-ante measures [4,5]. Determining the role of ex-post enforcement in a spectrum sharing scheme is of significant importance since spectrum sharing will inevitably result in interference events. To evaluate the role of the ex-post enforcement approach, we will consider numerical examples where we compare the cost of the ex-post only enforcement to the cost of the ex-ante only enforcement on one of the suggested bands for spectrum sharing (1695-1710 MHz). The cost of the ex-post enforcement in our model depends on the penalty value that Primary User (PU) uses to control interference events and the probability of detecting the interference. The penalty value depends on two factors which are changeable and unchangeable enforcement costs. The cost of the ex-post only enforcement has two variables that affect it, which are probability of detection; and the changeable enforcement cost. The numerical results show how these two variables affect one another, and their effect on the radius of the penalty zone. It also shows the maximum changeable enforcement cost that would be feasible.
\end{abstract}

\section{Introduction}

It seems inevitable that future wireless systems will include a shared spectrum. Shared spectrum can be viewed as a rearrangement of rights among stakeholders [1] that will require enforcement. Spectrum sharing may obtain many behaviors of management between the sharing entities. Sharing entities are the license holder or the spectrum incumbent who is called Primary User (PU) and the Secondary User (SU) who is using the spectrum temporarily.

Demsetz [2] indicates that enforcement is a key factor of any property rights management and Shavell [3] argues that the timing of the enforcement action (ex-ante or ex-post) plays an important role. The emphasis in commercial-government sharing in the US has been on ex ante measures [4,5].

It has been posited that a system built on efficient ex-post enforcement would reduce the opportunity cost of the ex ante measures. Determining the role of ex-post enforcement in a spectrum sharing scheme is of significant importance since spectrum sharing will inevitably result in interference events. This paper will evaluate the role of ex-post enforcement by modeling how an ex-post only enforcement scheme might work, and what the limits are on its effectiveness. In particular, there are a number of 
factors to consider, including the cost and time of adjudication as well as how well the penalty is calibrated to the value of the communication.

To examine the role of ex-post enforcement in a spectrum sharing regime, we study an ex-post-only regime. To determine whether (and when) this approach is superior to an ex-ante approach, we build a model of a geographic region with geographically distributed Secondary Users (SU) and a single Primary User (PU). Aggregate signal power of the secondary users will be calculated the Primary User's (PU's) antenna. The number of excluded secondary users will be determined based on an ex-ante approach that uses exclusion zones. We will plot the opportunity cost of the exclusion zones for varying values of Secondary User communications.

To evaluate ex-post enforcement, we posit an adjudication system that penalizes the Secondary User (SU) for each interference event received at the PU's antenna. In our study, the penalty would be proportional to the lost value of the lost data by the PU plus the expected increase in enforcement costs occasioned by it. More punitive penalties could be possible as well. The SU then optimizes their transmissions so that the net value of a sequence of transmissions is positive.

There are a number of phenomena that we study in this scenario. First, as the value for SU transmissions increase, SU may find it valuable to risk a higher interference penalty by transmitting closer to the PU's antenna. This results in dynamic and self-determined "exclusion zones".

The above approach assumes that adjudication is immediate and costless. To determine the bounds of adjudication costs, we determined the hypothetical cost level of a region that is equivalent to an exclusion zone in ex ante enforcement. Having achieved that, we reasoned about the effectiveness of an ex-post enforcement system and its technical requirements.

Ex-post enforcement must play a role in practical spectrum sharing systems. Despite this, it is not a topic that has attracted much attention in the research literature, with the notable exception of the work by Sahai and his co-authors (see, for example [6]). In this paper, we examine the behavior of a pure ex-post enforcement system (based on economic penalties) and compare it to pure ex-ante approaches. The results of this study will help researchers develop feasible approaches to adjudication and will help policymakers balance the use of ex-ante and ex-post enforcement techniques in spectrum sharing regimes.

This paper is organized as follows: section 2 will give the motivation behind this work and a brief historical background on the enforcement and how it was introduced in spectrum sharing regulation and enforcement timing. Section 3 demonstrates ex-post enforcement and modeling it in the spectrum sharing phenomena. Section 4 will examine and evaluate that approach, comparing it to the existing exante enforcement. The last section concludes this work and proposes future research.

\section{Motivation}

The Federal Communication Commission (FCC) has begun gradually adapting its policies to include spectrum sharing. In 2002, the Spectrum Policy Task Force (SPTF) supported the idea of using the market 
method to utilize spectrum dynamically and efficiently. In 2003, FCC allowed the spectrum license holder to apply spectrum leasing options for wireless services. In 2012 [7] the President of the United States called for $500 \mathrm{MHz}$ of additional spectrum for mobile broadband. The National Telecommunication and Information Administration (NTIA) [8] offered several bands to support this effort through spectrum sharing. The offered bands include the $1695-1710 \mathrm{MHz}, 1755-1780 \mathrm{MHz}, 3500-$ $3650 \mathrm{MHz}, 4200-4220 \mathrm{MHz}$, and $4380-4400 \mathrm{MHz}$. We will focus on the $1695-1710 \mathrm{MHz}$ band in this paper because the problem setup is straight forward; other bands will be studied in future.

These bands can be available for spectrum sharing with two main restrictions. The first is that the Signal Interference to Noise Ratio (SINR) limitation of $-10 \mathrm{~dB}$ that cannot be exceeded by the Secondary Users (SUs). The second is geographic limitations, called exclusion zones, in which spectrum may not be shared. The radii of these exclusion zones vary between 72-121 km, depending on the specific site. The lengths of the radii were given based on particular wireless systems used in their report. The length of the radii was established to prevent the Primary Users (PUs) from harmful interference. The exclusion zones will cover heavily populated areas that may reduce the incentives of the SUs to share. These two restrictions are clearly examples of ex-ante enforcement and do not consider any ex-post measures that might be implemented.

\subsection{Enforcement}

The general characteristics of the enforcement of rights were explained in many papers, but it was applied to spectrum sharing in [5]. These characteristics are [3, 5]: 1) enforcement timing action (ex-ante or ex-post); 2) sanctions form; 3 ) party (ies) of carrying out the enforcement.

In the past, the FCC assigned static spectrum bands to each user. Using this approach it was possible, to prevent most interference between users. With the revolution in the telecommunication industry in the last two decades and the lack of spectrum bands, the federal government proposed certain bands to be shared $[7,8,9]$ which leads to a rearrangement of rights [10]. These new configurations of rights require enforcement systems if they are to be viable.

\subsubsection{Ex-Ante and Ex-Post Enforcement}

As mentioned above, Shavell [3] argues that the timing of the enforcement action plays an important role in any enforcement regime. Enforcement actions can take place before (potential) interference events (ex-ante enforcement), or afterward (ex-post enforcement). Thus, ex-ante enforcement procedures consist of prevention mechanisms that shape the activity before the interference occurs. Examples of ex-ante enforcement are the exclusion zones and the SINR limitations. In contrast, ex-post enforcement consists of corrective measures after interference has occurred. The corrective measures may include penalties, product recall, modifications to spectrum sharing rights between PUs and SUs, or revocation of spectrum sharing licenses.

Practical enforcement schemes have ex-ante and ex-post enforcement that are linked together. The design of the overall enforcement system may give more emphasis to one or the other. 


\section{Model}

In this paper, we will build our argument on one of the proposed bands for sharing, the $1695-1710 \mathrm{MHz}$ frequency bands. This spectrum band was introduced by the NTIA for spectrum sharing between Federal/non-federal and commercial usage. In [8], the NTIA report mentioned that sharing strategy on this band should be limited to commercial systems operations which are LTE mobile uplink use only. That means the Primary Users (PU) are the Federal agencies and the Secondary Users (SU) are the commercial mobile operators. This band was chosen to build our scenario because the PU (license holder) uses the band for fixed communication services, and this band is suitable for mobile phone services. The PUs for band are Meteorological-Satellite (MetSat) and Meteorological Aids (MetAids) for space-to-earth and radiosondes links. The reasons for choosing this band are:

1) This band is suitable for LTE mobile network (which is the SU in this model),

2) The available bandwidth suggests that there will be a single SU, simplifying the enforcement problem,

3) The PU of the spectrum used fixed earth stations (which is the incumbent of the band for this model), and

4) Two of the exclusion zones for this band are for Suitland, Maryland and Wallops Island, Virginia. These exclusion zones cover Richmond city of Virginia State, the Washington DC metropolitan area which is the seventh largest metropolitan area, and Baltimore MD metropolitan area.

The population density only for Washington metropolitan area is 5.9 million people. The value for these covered areas approximately is worth $\$ 119$ million [5] which is a good incentive for SU to pay for sharing the spectrum within these areas. This value was calculated using the spectrum value opportunity that is used by the wireless operator to calculate spectrum value. The spectrum value opportunity is calculated by the population that each $\mathrm{MHz}$ of spectrum reaches (MHz-POP). In our model, we will assume that the value of this band is $\$ 1$ per MHZ-POP which is the same value that had been used in McHenry and his colleagues work [11]. The LTE required bandwidth by the ITU is $20 \mathrm{MHz}$, but we will use the available bandwidth for the band $1695-1710 \mathrm{MHz}$ which is $15 \mathrm{MHz}$.

\subsection{Spectrum Sharing}

The PU will share the spectrum within the suggested exclusion zones if (1) the SUs agree on the spectrum sharing rights that includes the SINR limits and (2) if any interference event occurs the SUs will be penalized. The exclusion zone in this model is built on is $90 \mathrm{~km}$ which is almost the mid-point between the proposed exclusion zones by the NTIA $(72-121 \mathrm{~km})$ and because it is equal to the same radius that had been suggested by the NTIA for the Suitland, Maryland exclusion zone.

\subsection{Enforcement}

An ex-post only regime will be used in the model. The ex-post enforcement will include penalties and modifications to spectrum sharing rights between PUs and SUs, if an interference event occurs. 


\subsubsection{Detection of Interference event}

To identify the interference events that affect the PU's received signal and are caused by the SU'S uplink signal, a sensing system must be built around the PU (which is an Earth Base Station in our model). The sensor network will detect the aggregate signal energy attributable to the SU. If the signal energy reaches the noise level, interference is detected and the SU will be penalized. If the signal energy is below noise level, it is not detectable.

\subsubsection{Ex-post enforcement cost}

In the ex-post enforcement in our model, PU uses penalties to control interference events. It acquires assured costs in correlation with the enforcement procedure. These costs have an effect on the value of penalties and the level of enforcement (the probability of detection of the SUs whose SINR exceeds the limit -10dB).

Polinsky and Shavell [12] argue that there are two types of enforcement costs: unchanging enforcement costs and changeable enforcement costs. Unchanging enforcement costs are costs that do not depend on the number of SUs that exceed the interference limits. These costs would include, for example, the expenses of detecting the interference in the shared spectrum. Changeable enforcement costs depend on the number of SUs involved in the interference events; these costs range from attributing interference to the appropriate party and penalizing the interferer, to collecting the penalties.

Polinsky and Shavell [12] argued about those two types (the unchanging enforcement and the changeable enforcement) costs and how they directly and indirectly affect the penalty value and the probability of detection. The unchanging enforcement costs do not directly affect the penalty value because these costs do not vary as the number of SUs who interfered with the PU increase. When SU interferes, the expense of measuring the interference level is not affected. However, unchanging enforcement costs do control the optimal probability of detection; they therefore indirectly affect penalty values since the factor by which the interference is increased is a function of the probability of detection.

The probability of detection depends on both types of enforcement costs. If changeable enforcement costs are high, the probability will be low because enforcement will be expensive; for adequately high changeable costs, the probability will be zero. Likewise, if unchangeable enforcement costs are not very dynamic then the probability will be low; in the extreme, it will be zero. If it is expensive to raise the probability; the probability will be higher but may be less than one. And if the probability could be raised with no additional cost, it may not be desirable to raise it because changeable enforcement costs may then become extreme.

\subsubsection{Penalty}

Penalties are imposed on the SUs if they violate the terms of spectrum sharing rights. There are two approaches to determine penalties: remunerative and punitive. The punitive penalty means that if interference events occur, the SU will pay much more than the real value of the lost data during 
reception by the PU. By contrast, a remunerative penalty seeks to compensate the PU for the value of the loss due the interference event. In this paper, we will use the remunerative approach.

The PU charges a Penalty $(\$ I)$ to the SU that recovers his (1) transmission loss due to interference and (2) the changeable enforcement costs $(\$ C)$. Undetected interference should not increase the penalty. The PU cannot know for certain what $\alpha$ is, so it is a private estimate. It could adjust the Penalty ( $\$ I)$ by $\alpha$, but not the changeable cost $(\$ C)$. The penalty function will be as follows:

$$
P_{P U}=\alpha(I+C)
$$

Where $\alpha$ is the probability of detection, and the PU cannot know for certain what $\alpha$ is, so it is a private estimate. It could adjust the Penalty $(I)$ by $\alpha$, but not the changeable cost $(C)$.

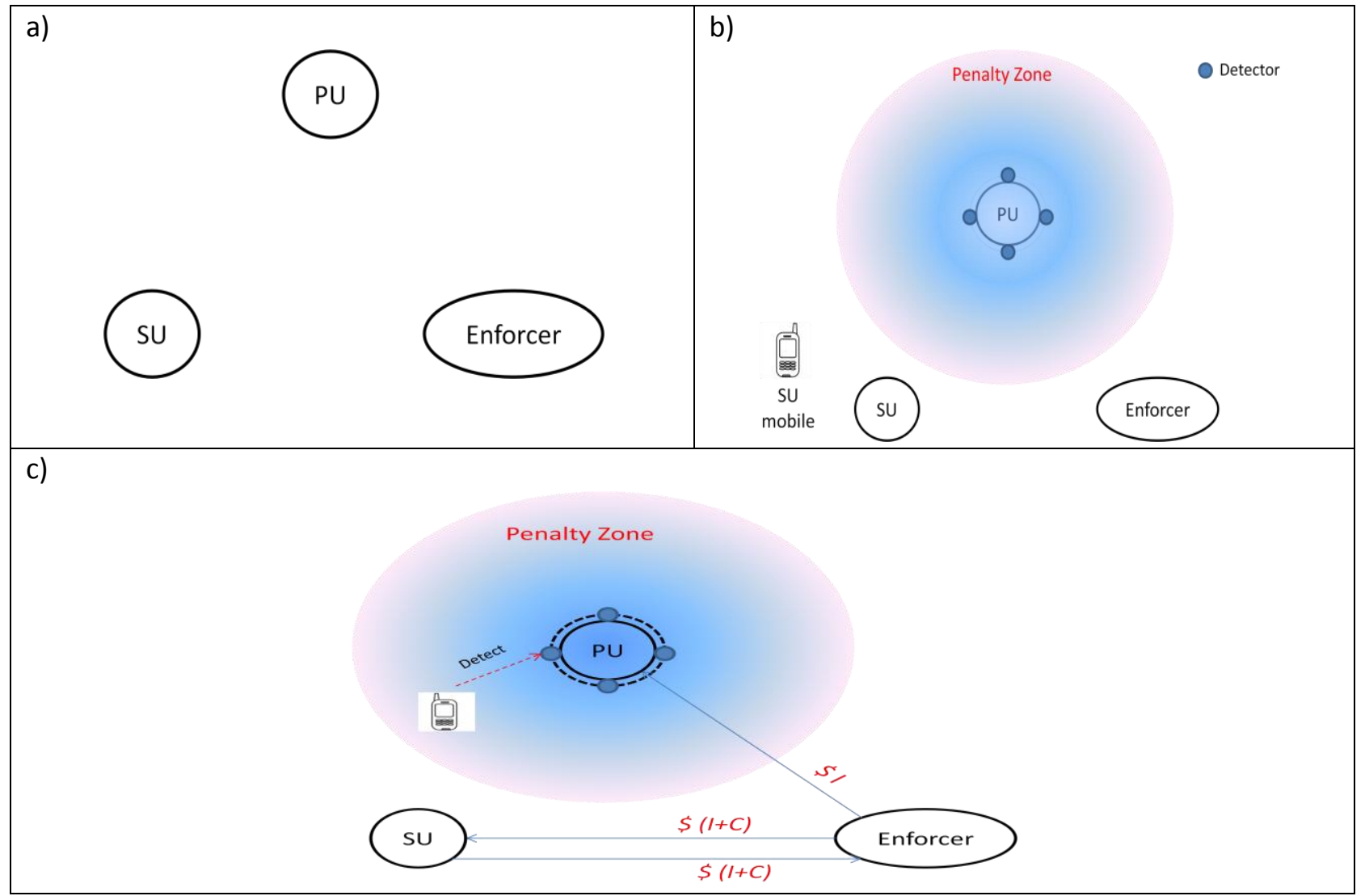

Figure 1: The penalty will include the value to recover PU transmission and the changeable enforcement cost

Figure 1-a shows that we have three entities which are the PU, SU and third party Enforcer. SU uses the bands that PU is using to reach its base station. Figure 1-b shows that the third party enforcer is using sensor antennas around the PU to detect the SINR to the PU. The sensor antennas will have a range to detect the interference events, which is called the penalty zone. Although, the sensor antenna will detect the interference event with probability of detection $\alpha$. The rate of the probability of detection depends on the quality of the sensor antenna that the enforcer deployed around the PU. When the SU transmits within the penalty zone, there is probability of detection $\alpha$. Figure 1-c shows the revenue flows if an interference event is detected and the enforcer penalizes the SU with the value of $\$(I+C)$. 
Then the enforcer sends $\$ I$ to the PU after receiving the penalties from the SU. Here we have two actions in this scenario which are the signal power and the revenue. If we assume that the SU knows the value of $I$ and $C$, the SU can make a judgment about $\alpha$ to estimate $\alpha(I+C)$.

The SU will take the decision to transmit based on:

- $\quad$ From the propagation model, SU estimates of the received aggregate signal power at PU or SINR $\geq-10 \mathrm{~dB}$

- $\quad$ Based on estimated signal power, SU estimates $\alpha$ (presumably SU knows $I+C$ )

- If value of transmission is $\geq \alpha(I+C)$, the $\mathrm{SU}$ will transmit

- Otherwise if the value of transmission is less than $\alpha(I+C)$, the SU will not transmit

Though, $\alpha$ is a function of estimated aggregate signal power $\left(\widehat{P_{P U}}\right)$ and detector sensitivity $\left(q_{d}\right)$. We know that $\alpha$ should increase as $\widehat{P_{P U}}$ goes up and $\alpha$ should goes down as $q_{d}$ goes down.

A profit maximizing SU would make a decision to transmit based on the value $s /$ he receives from the transmission $\geq \alpha(I+C)$, where $\alpha$ is the SU's privately estimated probability of being caught. The SU would have a better estimate of the probability of detection than the PU does, since they know when they transmitted and when they were penalized.

Since we cannot know the value of $\alpha$ is, we start by assuming a perfect system $(\alpha=1)$. It will be reasonable to assume that both the changeable and unchangeable enforcement costs influence the value of $\alpha$, which may result in an optimal investment in enforcement systems.

To estimate the lost data value, we use the cost to receive $1 \mathrm{MHz}$ from a satellite link as a proxy. Our research has shown that building, launching, and operating a new satellite with 15 transponders for ten years will cost around $\$ 300$ million ${ }^{1}$. The cost of leasing a transponder costs approximately $\$ 2$ million per year. The transponder bandwidth is $36 \mathrm{MHz}$, which means that this $1 \mathrm{MHz}$ lease cost is approximately $\$ 0.0018$ per second. To estimate the duration of an interference event, we assume that this would be the average length of an SU session. For a voice call, this would be $2 \mathrm{~min}$, for a data session, this would be the duration of a session. We will go with 2 min as a starting point, so this would be $0.0018 * 2 * 60$. The SU will use the $15 \mathrm{MHZ}$ bandwidth which means that $(0.0018 * 2 * 60 * 15)$ the value of the lost data for each interfering event will cost $\$ 3.24$. Although, we will assume that the maximum changeable enforcement cost that can be reached in this study is $\$ 3.24$ to make it more feasible for the reader.

\subsubsection{Opportunity Cost}

The opportunity cost in the case of the spectrum is the value of the next highest alternative use of that spectrum when using ex-ante enforcement or ex-post enforcement. This value will be represented using the ratio between ex-post enforcement over the ex-ante enforcement. We will look at the opportunity cost of each option to find the most valuable opportunity. If we choose ex-ante enforcement only, we lose a number of SUs who will not transmit within the exclusion zone but we will gain no interrupted or

\footnotetext{
${ }^{1}$ http://www.satsig.net/ivsatcos.htm
} 
lost data to the PU. If we choose the ex-post enforcement only within the penalty zone, we will allow transmission for SUs within the exclusion zone. However, the PU operation may be interrupted and loose data if the SUs transmit within the penalty zone and the SU signal SINR exceeds $-10 \mathrm{~dB}$. We assume that there is a third party enforcer who penalizes SUs whenever the SU signal SINR exceeds -10dB (which will be called interference event in this paper).

We assume that we have potential SUs uniformly distributed in the shared field. The spectrum value opportunity is calculated by the population that each $\mathrm{MHz}$ of spectrum reaches ( $\mathrm{MHz}-\mathrm{POP}$ ). In our model, we assume that the value of this band is $\$ 1$ per MHZ-POP which is the same value that had been used in McHenry and his colleagues work [11]. We will use the available bandwidth for the band $1695-1710 \mathrm{MHz}$ which is $15 \mathrm{MHz}$. We can calculate the opportunity cost over the exclusion zone by counting the number of all the potential SUs' values. For each one of these shall Secondary User Service Provider (SUSP) provide the service to its client or not?

1- In the ex-ante case, we can transmit if the SU is outside the exclusion zone. The value of the transmission realized by the SUs in the exclusion zone model will be:

$$
C_{e x}=n_{e x} \times V=n_{e x} \times \$ 1 P O P \text { per } \mathrm{MHz} \times 15 \mathrm{MHz}
$$

Where $n_{e x}$ is the number of SUs outside of the exclusion zone and $V$ is the value of the transmissions per SU.

2- In the ex-post case, if the SUs entered the exclusion zone, to which one of them shall the transmission continue on as SU service provider? The following model demonstrates:

$$
S U_{\text {Transmit }}=\left\{\begin{array}{llr}
\text { Yes: } & \text { if } & \text { outside e.z }(\text { Ex }- \text { ante }) \\
\text { Yes: } & \text { if } & \alpha(I+C) \leq \text { Transmit value } \\
\text { No: } & \text { else } &
\end{array}\right.
$$

From the previous two conditions, SU can transmit if the mobile device is outside the exclusion zone, or when the probability of detection $(\alpha)$ times the penalty value is less than or equal the value of transmission. We will assume that the transmission value is equal to the transmission value using the exante enforcement $C_{e x}$ because if this value is exceeded there will be no incentive to use the ex-post enforcement. The ex-post enforcement costs would be calculated by:

$$
C_{e p}=N_{S U} \times P_{P U}=N_{S U} \times \alpha(I+C)
$$

As mentioned in the penalty function, the probability of detecting an interferer is $\alpha$. The SU will be penalized whenever PU sensors detected by the SINR exceed $-10 \mathrm{~dB}$. $N_{S U}$ refers to the number of detected SUs.

By getting the ratio between the two costs of ex-ante enforcement and ex-post enforcement, we can predict if the SU can transmit using the ex-post enforcement when the ratio is less than or equal to 1.

$$
C_{e p} \leq C_{e x} \rightarrow \frac{N_{S U} \times \alpha(I+C)}{n_{e x} \times V} \leq 1------(1)
$$




\subsubsection{Signal Interference-To-Noise Ratio (SINR)}

The equation for the SINR can be expressed as:

$$
\operatorname{SINR}_{i}=\frac{P_{r P U} G_{i i}}{\sum_{j \neq i} P_{r S U} G_{i j}+n_{i}}
$$

The signal to interference and noise ratio varies with the transmission parameters for SU. It depends on the distance between the PU and the SU, the received power of the PU and SU, the transmitter density, the antenna parameters of the $\mathrm{SU}$ and $\mathrm{PU}$, and $n_{i}$ is the noise. The received power is:

$$
P_{r}=P_{t}(d B)+G_{R}(d B)+G_{T}(d B)-P a t h \operatorname{loss}(d B)
$$

Where $P_{r}$ is the received power, $P_{t}$ is the transmitted power, $G_{R}$ is the maximum receive antenna gain, $G_{t}$ is the maximum transmit antenna gain.

To get the received power the path loss must be found first. And to get the path loss, two equations will be used:

1- Free Space Path Loss: FSPL $=\frac{4 \pi \mathrm{f}_{\mathrm{c}} d}{\mathrm{c}}$, where $\mathrm{f}_{\mathrm{c}}$ is the center frequency, $\mathrm{c}$ is the speed of light, and $d$ is the distance. Free Space Path Loss equation used to get the desired received power by the earth station.

2- To get the path loss the COST-231 model will be used. This is a propagation model funded by the European COST-231program. The COST-231 propagation model can be applied to the frequency range (1500- $2000 \mathrm{MHz})[13]$ :

$$
\begin{aligned}
P L=46.3+ & \left(33.9 \times \log _{10}(\mathrm{fc})\right)-\left(13.82 \times \log _{10}(\mathrm{ht})\right)-\mathrm{a}\left(\mathrm{h}_{\mathrm{re}}\right)+\left[44.9-6.55 \times \log _{10}(\mathrm{ht})\right] \\
\times & \times \log _{10} \mathrm{~d}(\mathrm{i})+\mathrm{C}
\end{aligned}
$$

Where $P L$ is the path loss, $f_{c}$ is the center frequency, $a\left(h_{r e}\right)$ is the mobile antenna correction factors for the effective antenna height in $\mathrm{dB}$ :

$$
\mathrm{a}\left(\mathrm{h}_{\mathrm{re}}\right)=\left\{\begin{array}{l}
8.29\left(\log 10\left(1.54 \mathrm{~h}_{\mathrm{re}}\right)\right)^{2}-1.1 \text { if fc } \leq 300 \mathrm{MHz} \\
3.2\left(\log 10\left(11.75 \mathrm{~h}_{\mathrm{re}}\right)\right)^{2}-4.98 \text { if fc }>300 \mathrm{MHz}
\end{array}\right.
$$

$h_{t e}$ is the effective transmitter antenna height ranging from 30 to 200 meter, $h_{r e}$ is the effective receiver antenna height ranging from 1 to 10 meters, $d$ is the distance between the transmitter and the receiver in kilometers, and the value of $C=0 d B$ for medium-size city and $C=3 d B$ for metropolitan areas.

3- Then to calculate the noise the following equation can be used:

$$
\mathrm{n}_{\mathrm{dB}}=\mathrm{K}+\mathrm{T}_{\mathrm{o}}+\mathrm{F}+10 \times \log _{10}(\mathrm{BW})
$$

Where $\mathrm{K}$ is 198.6, $\mathrm{T}_{\mathrm{o}}=24.6 \mathrm{~dB}, \mathrm{~F}$ is the noise figure, and $\mathrm{BW}$ is the bandwidth.

\section{Numerical Results}

Figure (2) shows the SU as a mobile device transmitting near the earth base station (PU). The PU is receiving two signals; the desired received signal (the downlink signal by Federal Metrological-satellite) 
and the interfering signal by the mobile device (SU). As shown in Figure 1, the SU will not be penalized as long as its interfering signal does not exceed the interference limits $(-10 \mathrm{~dB})$. When the SU moves closer to the PU base station and the interference event is detected; the enforcer will charge the SU with $\$(I+C)$. Then the enforcer sends $\$ I$ to the $\mathrm{PU}$ after receiving the penalties from the SU.

We assumed: 1) the center frequency at $1702.5 \mathrm{MHz}$. 2) EIRP value includes the effects of antenna gain, antenna efficiencies, transmitter power, coupling and wave guide losses. And when the EIRP is known, no additional information about the transmitter is required. The EIRP used in the model is 8.1dBW2. 3) the distance between the satellite and the earth station used $35785 \mathrm{~km}$ (approximately 22,236 mile). 4) Free Space Path Loss equation used to get the desired received power by the earth station.

For the uplink of LTE mobile network (SU) we assumed: 1) the center frequency at $1702.5 \mathrm{MHz}$. 2) COST231 used to calculate the path loss to get the interfered received power. 3) C= 3 in the COST-231 because we are going to use it in the metropolitan area. 4) Received antenna height (ht) used 30 meters. 5) Transmitter height used 1.5 meter. 7) Transmitted power used $23 \mathrm{dBm}$ which is the highest transmission power for the LTE mobile phones. 7) 100,000 uniformly distributed mobile phones (SU) at a time.

The noise value used is 0 Watt because we assume the antenna receiver is engineered to deal with and reject normal noise.

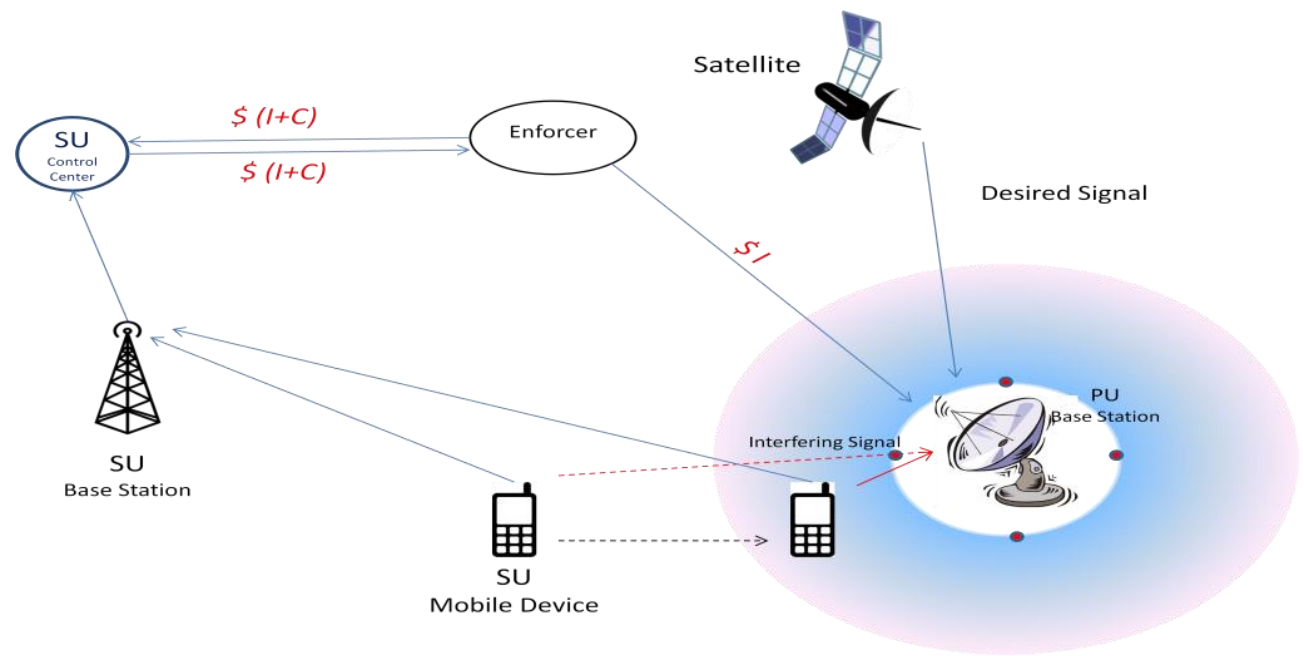

Figure 2: the received signals at the PU base station

To examine the role of ex post enforcement in a spectrum sharing regime, we study an ex-post-only regime. To determine whether (and when) this approach is superior to an ex ante approach, we build a simple model of a geographic region with geographically distributed secondary users and a single primary user. Aggregate signal power of the secondary users is computed at the primary user's antenna (see figure 3). The number of excluded secondary users will be determined based on an ex ante approach that uses exclusion zones (see figure 3-a).

\footnotetext{
${ }^{2}$ This value based on the ITU-P recommendation S.A. 1026
} 

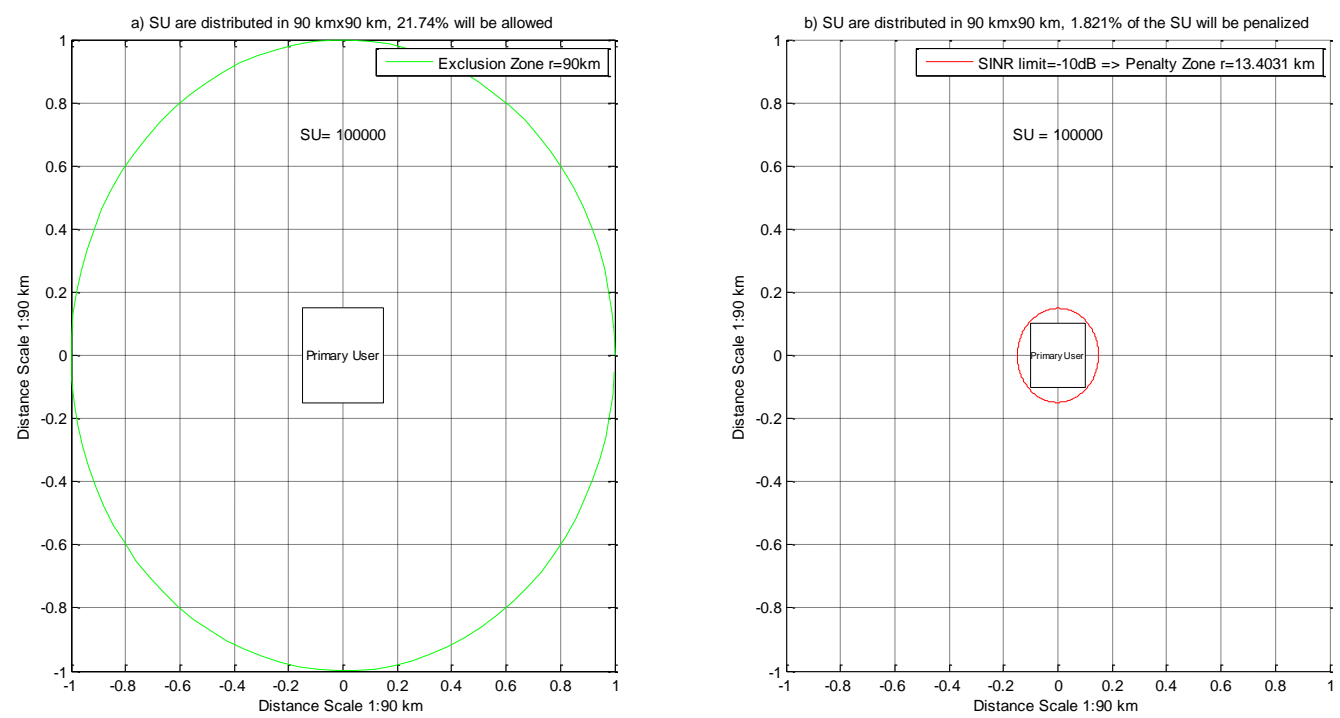

Figure 3: percentage of excluded and penalized SU

Figure 3-a is an example for ex-ante only enforcement, when there are $n=100,000$ SUs uniformly distributed in the area of $90 \mathrm{~km} \times 90 \mathrm{~km}$. This area includes an exclusion zone such that only $21.7 \%$ of the SUs (those outside of the exclusion zone) are allowed to transmit their signal. On the other hand, if expost only enforcement is used by penalizing SUs who interfere with the PU by using the interference limitation (SINR limit is fixed to $-10 \mathrm{~dB}$ ) and any SU exceeds that level will be penalized (Figure 2-b: SINR limit is fixed to $-10 \mathrm{~dB}$, and used the same $n=100,000 \mathrm{SUs}$ ), then all the $100,000 \mathrm{SU}$ will be allowed to transmit and only $1.7 \%$ will be penalized. And if the PU decides to make the penalty zone a no transmit zone, then the radius of no transmit zone would be smaller for ex-post only enforcement than for exante only enforcement.

And to make it more feasible to the reader, figure 4 shows an approximation when implementing the exante only verses ex-post only enforcements. Figure 4-a shows two of the exclusion zones denoted by the red circles (ex-ante enforcement only) which are Suitland, MD and Wallops Island, VA. These exclusion zones cover Richmond, VA, Washington metropolitan area (Washington DC is part of it) which is the the seventh largest metropolitan area, and Baltimore MD metropolitan area. We can see that the PU will not share the band $(1695-1710 \mathrm{MHz})$ within these two exclusion zones and the SUs can transmit only if they are outside these zones. Figure 4-b shows when the ex-post only is used, the penalty zones which are denoted as blue circles. The penalty zones will be much smaller than the exclusion zone. The SUs can transmit within these two zones but they will be penalized. In addition, spectrum can be shared in some major cities that were within the exclusion zones. 
a) Ex-ante only enforcement: two of the exclusion zones which are Suitland, MD and Wallops Island, VA

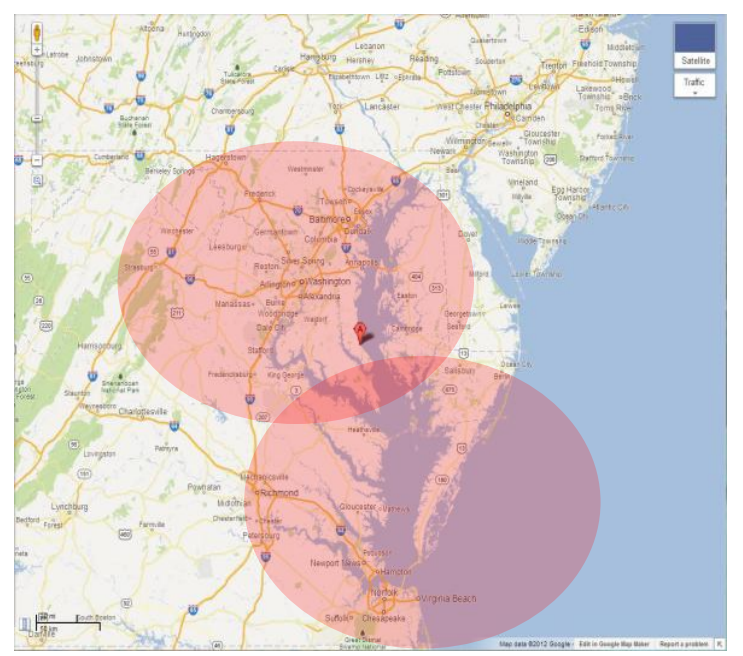

b) Ex-post only enforcement: spectrum can be shared in all the area, and penalty zone is much smaller than exclusion zone

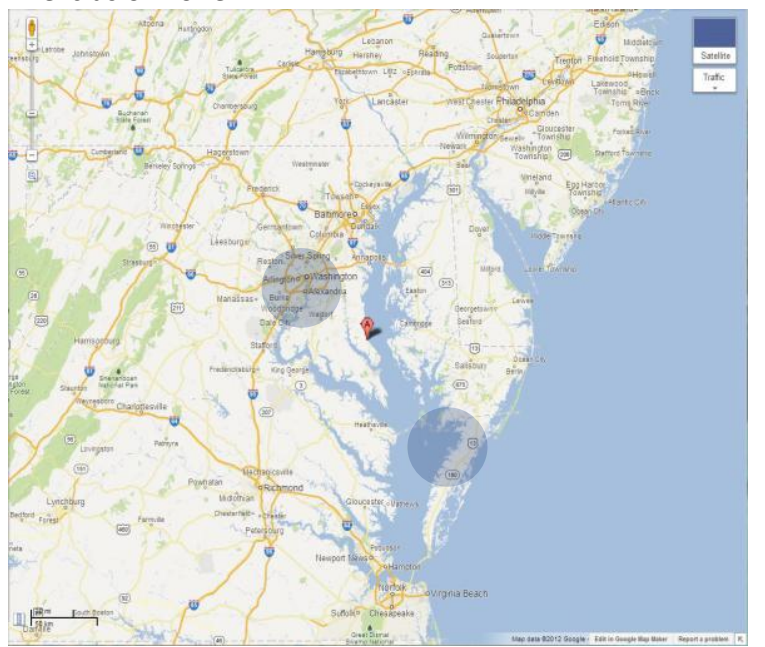

Figure 4: comparison between the radii of the exclusion zones and penalty zones.

\subsection{Ex-post enforcement and Penalty zone variation}

In this section we evaluate the role of the ex-post only enforcement. As mentioned, the cost of the expost enforcement depends on the penalty function. The penalty function has two variables that affect the radius of the penalty zone which are the changeable enforcement cost and the probability of detection. The radius of the penalty zone will have a direct impact on the SU user decision.

Figure 5 shows how the changeable enforcement costs and the probability of detection are affecting the radius of the penalty zone. Figure $5-a$ shows that varying the changeable enforcement costs affect the penalty zone radius with two values of probability of detection ( $\alpha=100 \%$ and $75 \%$ ). The penalty zone radius increases as the changeable cost of enforcement increases. And the maximum feasible changeable enforcement cost occurs when the radius of ex-post-only matches the ex-ante-only radius when penalty zone radius equals $90 \mathrm{~km}$. This can be seen with $\alpha=100 \%$ the changeable enforcement cost $C \approx \$ 18.4$, and with $\alpha=75 \%$ the changeable enforcement cost $C>\$ 25$. Figure 5 -b shows that when the probability of detection is zero the radius of the penalty zone is zero and as the probability of detection goes up the radius of the penalty zone goes up. The values of the changeable enforcement costs that had been used were $\$ 3.24$ which is the same value as the lost data and $\$ 18.4$ which is the maximum feasible value in figure5-a. it can be seen that if the changeable enforcement cost becomes more expensive (when the changeable enforcement costs increased from \$3.24 to \$18.4) with the same probability of detection that will impact positively on the radius of the penalty zone which may increase the income for the PU. We can understand from this figure that the effect of the changeable enforcement costs $(\$ C)$ on the increment of the penalty zone radius will be greater when the probability of detection is higher and vice versa. 
a)

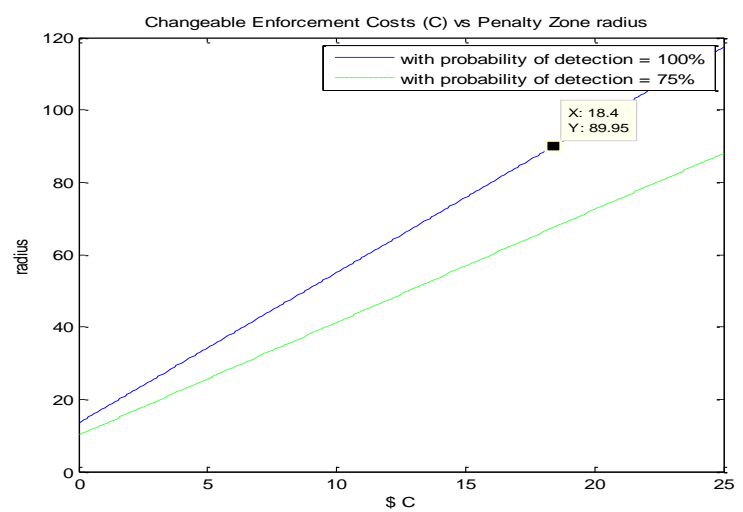

b)

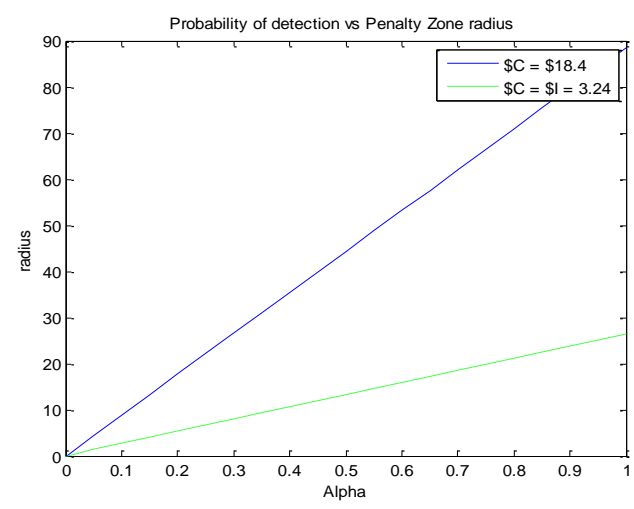

Figure 5: Changeable enforcement costs and probability of detection dependability

\subsection{SU transmission options}

To evaluate ex-post enforcement (figure 6), we need to predict the cost of the ex-post only enforcement and compare it with the ex-ante only enforcement. To predict the cost of the ex-post only enforcement by calculating the number of the penalized SUs which is equal to $C_{e p}=N_{\mathrm{SU}} \times \alpha[(\$ 0.0018 \times$ $15 \mathrm{MHz} \times 120)+C]$. In this case, the SINR= $-10 \mathrm{~dB}$ as the interference limit is used and by that the radius of the penalty zone would be obtained. Though, when we have 100,000 SU uniformly distributed around the PU in $90 \times 90 \mathrm{~km}$. The assumed adjudication system by an enforcer would penalize the secondary user SU for each detected interference event with a probability of detection. The best case scenario is when the probability of detection is $100 \%$ and there are zero changeable enforcement costs $(\alpha=1, C=\$ 0)$. Then, the radius of the penalty zone would be $13.4 \mathrm{~km}$ and $1.7 \%$ out of $100,000 \mathrm{SUs}$ will be detected and penalized (see figure 3-b).

On the other hand, we can predict the cost of the exclusion zone by getting the allowed SUs which is $C_{e x}=n_{S U} \times \$ 1 \times 15 \mathrm{MHz}$ (figure 3-a). Figure 6 shows the ratio between the cost of the ex-post enforcement and the ex-ante enforcement versus the radius of the penalty zone.

By using the ratio equation (1) in the opportunity cost section which is the ratio between the ex-ante enforcement and ex-post enforcement. The ratio equation will be as follows:

$$
C_{e p} \leq C_{e x} \rightarrow \frac{N_{S U} \times \alpha(I+C)}{n_{e x} \times V} \leq 1
$$

It can be predicted when the SU can transmit using the ex-post enforcement if the ratio is less than or equal to one. The ex-post only enforcement is superior to an ex ante approach as long as the ratio is less than one. 


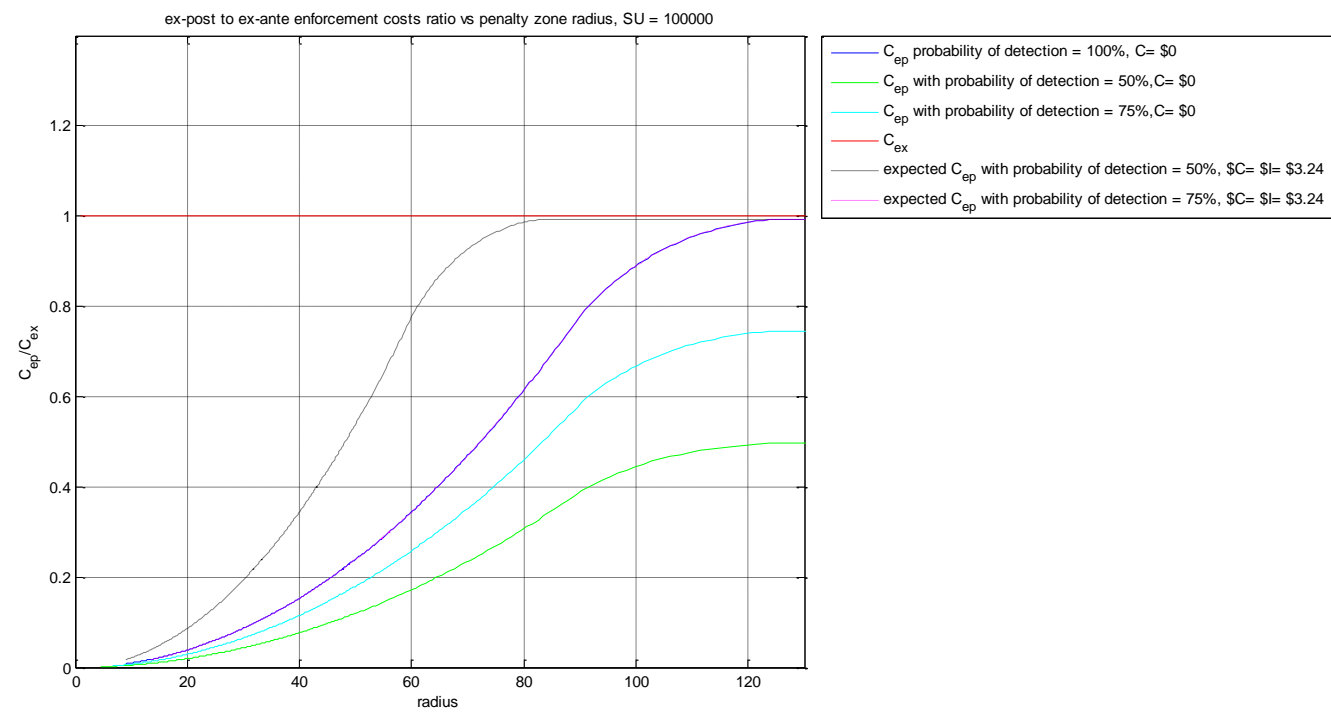

Figure 6: Ex-pot to Ex-ante enforcements ratio vs penalty zone radius

Figure 6 shows the impact of the varying probability of detection and changeable enforcement cost on the radius of the penalty zone and ratio between the cost of ex-post only enforcement over the cost of ex-ante only enforcement. If the enforcer is using $50 \%$ as the probability of detection with the changeable enforcement cost of $\$ 3.24$, SU will find it valuable to transmit without being caught and penalized. Or, s/he may find it valuable to risk higher interference penalty by transmitting closer to the PU's antenna as long as the value for SU transmission increase and the radius of the penalty zone is less than $120 \mathrm{~km}$. When the enforcer increases the probability of detection to $75 \%$ with the same changeable enforcement cost of $\$ 3.24$ to catch more interferers and gain more income, the SU then need to optimize transmission so that the net value of a sequence of transmissions would be greater than one. That means the SU will transmit as long as the radius of the penalty zone is less than $80 \mathrm{~km}$. And if the radius of the penalty zone is set to more than $80 \mathrm{~km}$ the ex-post enforcement will be ineffective and have no incentive to the SUs. This results in dynamic and self-determined "exclusion zones". The SU needs to predict the probability of detection and the changeable enforcement cost in order to calculate the maximum penalty zone radius that is used by the enforcer to decide whether the SU is transmitting or not.

Also, figure 6 shows that when the changeable enforcement costs become more expensive $(\$ 3.24)$, the range of the penalty zone radius becomes smaller. That may lead to inefficient ex-post enforcement if the radius of the penalty zone is more than $80 \mathrm{~km}$.

\section{Discussion}

This paper examines the role of ex-post enforcement in a spectrum sharing regime. To determine whether (and when) this approach was superior to an ex ante approach, we built a simple model of a geographic region with geographically distributed secondary users and a single primary user. Aggregate signal power of the secondary users was computed at the primary user's antenna. The number of 
excluded secondary users were determined based on an ex ante approach that used exclusion zones. Then we showed how the changeable enforcement costs and the probability of detection are dependent on each other. We showed how the effect of the changeable enforcement costs $(\$ C)$ on the increment of the penalty zone radius will be greater when the probability of detection is higher and vice versa. By using the ratio between the ex-ante enforcement and ex-post enforcement, we predicted when the SUs could transmit using the ex-post enforcement if the ratio was less than or equal to 1 . In addition, we showed that when the changeable enforcement costs became more expensive, the benefit range for the $\mathrm{SU}$ of the penalty zone radius became smaller and led to inefficient ex-post enforcement.

\subsection{Varying the Changeable enforcement cost and probability of detection}

When the radius of the penalty zone increases the changeable enforcement cost increases. The maximum feasible changeable enforcement cost occurs when the radius of ex-post-only matches the exante-only radius.

\subsection{SU density (Appendix A)}

There are other variables that may affect the decision of the SU to transmit using the ex-post only enforcement or to go with the ex-ante enforcement. One of these variables is the SUs density within the exclusion zone. It can be predicted that the more dense the SU around the PU the more the SU would be penalized. Numerical results showed that the number of the penalized SUs goes down when the SUs were distributed in lower density (Figure 11).

\subsection{Other sensitivity analysis (Appendix A)}

This part of the paper evaluated the sensitivity of the Signal Interference-to-Nose Ratio (SINR), the penalty zone, and the penalty fluctuation on three important parameters: Secondary Users (SU) distance from the PU, desired received signal power, and interference received power. The first parameter showed that no matter how many SUs when the distances of the SU become less than $10 \mathrm{~km}$, the SINR decrement rapidly the closer the SU is to the PU receiver. For the desired received signal power parameter, SU was better at transmitting at lower power when transmitting closer the PU. SINR limit played an important role in assigning the ex-post only enforcement cost. The last parameter showed how the penalty zone fluctuated when the SU density changed around the PU.

\section{Conclusion and future work}

In this work we built our argument on one of the proposed bands for sharing which is $1695-1710 \mathrm{MHz}$ frequency range. We did not consider Bandwidth (BW) and noise. We examined the role of ex post enforcement in a spectrum sharing regime by studying an ex-post-only regime. We built a model of a geographic region with geographically distributed secondary users and a single primary user to determine whether (and when) this approach is superior to an ex ante approach. We assumed an adjudication system that penalizes the secondary user for each interference event detected at the PU's antenna to evaluate the ex-post enforcement. 
As the value for SU transmissions increase, users found it valuable to risk higher interference penalty by transmitting closer to the PU's antenna. This results in dynamic and self-determined "exclusion zones" which means the SU needs to predict the probability of detection and the changeable enforcement cost in order to calculate the maximum penalty zone radius that is used by the enforcer to decide whether transmitting or not.

The main purpose for this paper was to show how the cost elements of the ex-post only enforcement play together and how they affect the SU decision. It was shown that the radius of a no-transmit zone is smaller for ex-post only enforcement than ex-ante only enforcement. The radius of the penalty zone increases as the changeable enforcement cost increases. The maximum feasible changeable enforcement cost occurs when the radius of ex-post only matches the ex-ante only radius which is the limit on the ex-post only enforcement costs.

Together with the sensitivity of detection, this leads to engineering design objective for ex-post only detection and enforcement system. Such a system will most certainly have to be automated and is dependent on institutional factors.

The future work with this model will look at the structure of the enforcement system, the income stream for the PU, and how the PU behaves. We will build a hypothetical system to explore the technical and operational aspects that drive the costs of ex-post enforcement. We will model the income stream for the PU and how they respond to that; at some point the PU, may find it more valuable to collect interference penalties than to operate a system in that location. Later we will examine the practical enforcement schemes by having ex-ante and ex-post enforcement that are linked together.

\section{References}

1 M. B. Weiss, W. H. Lehr, L. Cui, and M. Altamaimi, "Enforcement in dynamic spectrum access systems," 2012.

2 H. Demsetz, "The Exchange and Enforcement of Property Rights," J Law \& Econ., vol. 7, p. 11, 1964.

3 Shavell, "The Optimal Structure of Law Enforcement," J Law \& Econ., vol. 36, p. 255, 1993

4 G. Locke, L. E. Strickling, and A. Secretary, "An Assessment of the Near-Term Viability of Accommodating Wireless Broadband Systems in the $1675-1710 \mathrm{MHz}, 1755-1780 \mathrm{MHz}, 3500-$ $3650 \mathrm{MHz}$, and 4200-4220 MHz , 4380-4400 MHz Bands," October, pp. 3500-3650, 2010.

5 M. Altamaimi, M. B. Weiss, and M. McHenry, "Enforcement and Spectrum Sharing: Case Studies of Federal-Commercial Sharing," Telecommunications Policy Research Conference, 2013.

$6 \quad$ K. A. Woyach, A. Sahai, G. Atia, and V. Saligrama, "Crime and Punishment for Cognitive Radios," in Proceedings of the Forty-Sixth Annual Allerton Conference on Communication, Control, and Computing, 2008.

7 PCAST, "REPORT TO THE PRESIDENT REALIZING THE FULL POTENTIAL OF GOVERNMENT-HELD SPECTRUM TO SPUR ECONOMIC GROWTH

8 Committee Commerce Spectrum Management Advisory, "CSMAC Working Group 1 (WG-1) 1695-1710 MHz ; Meteorological-Satellite," 18 June 2013.

9 G. Locke, L. E. Strickling, and A. Secretary, "An Assessment of the Near-Term Viability of 
Accommodating Wireless Broadband Systems in the $1675-1710 \mathrm{MHz}, 1755-1780 \mathrm{MHz}, 3500-$ $3650 \mathrm{MHz}$, and 4200-4220 MHz , 4380-4400 MHz Bands," no. October, pp. 3500-3650, 2010

10 L. Cui, M. M. Gomez, and M. B. Weiss, "Dimensions of cooperative spectrum sharing: Rights and enforcement," in Dynamic Spectrum Access Networks (DYSPAN), 2014 IEEE International Symposium on, 2014, pp. 416-426.

11 McHenry, Giulia and Bazelon, Coleman, "The Economic of Spectrum Sharing". TPRC41: the 41 Research Conference on Communication, Information and Internet Policy, March 31, 2013. Available at SSRN: http://ssrn.com/abstract=2242008 or http://dx.doi.org/10.2139/ssrn.2242008

12 A. M. Polinsky and S. Shavell, "Enforcement costs and the optimal magnitude and probability of fines," National Bureau of Economic Research1993.

13 "A guide to the wireless engineering body of knowledge (WEBOK), 2d ed." Reference \& Research Book News Dec. 2012. Academic OneFile. Web. 8 Jan. 2015. Available:

http://go.galegroup.com/ps/i.do?id=GALE\%7CA312255990\&v=2.1\&u=upitt_main\&it=r\&p=AON $E \& s w=w \& a s i d=12466$ ede5e760fb56d766a82ef4da1e7 


\section{Sensitivity Analysis}

\section{Appendix A}

In this part of the paper we evaluate the sensitivity of the Signal Interference-to-Nose Ratio (SINR), the penalty zone, and the penalty fluctuation on four important parameters: Secondary Users (SU) distance from the PU, desired received power, interference received power, and SU density.

Figure 7-a shows the exclusion zone with the radius of $90 \mathrm{~km}$ with $100,000 \mathrm{SU}$ uniformly distributed outside the exclusion zone. Figures 7-b and 7-c show how the SINR decline with distance; the closer SU the lower the SINR. In figure 7-b the minimum SINR is around $28 \mathrm{~dB}$. Then, figure 7-c shows the SINR drop when the $100,000 \mathrm{SU}$ are uniformly distributed in the exclusion zone and the PU is in the middle of the graph.
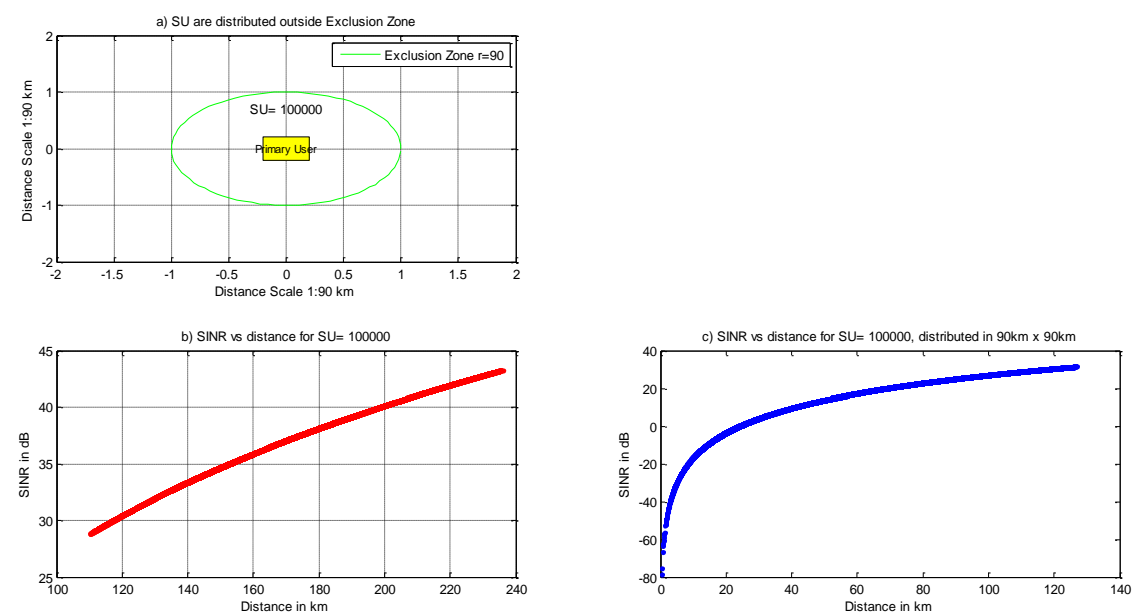

Figure 7: SINR when SU out and in the exclusion zone

Figure 8 shows that $100,000 \mathrm{SU}$ are uniformly distributed in the area of $90 \mathrm{~km} \times 90 \mathrm{~km}$ around the PU, PU EIRP is $8.1 \mathrm{~dB}, \mathrm{SU}$ transmitted power is $23 \mathrm{dBm}$, and SINR limit $[-10,-5,-1,20] \mathrm{dB}$. The results show the effect of changing the SINR limit on the radius of the penalty zone. Figure 9 shows the effect of changing the SINR limit on the percentage of the penalized SU. However, spectrum sharing idea becomes inefficient for the SU, if the SINR limit is higher than -1dB. 

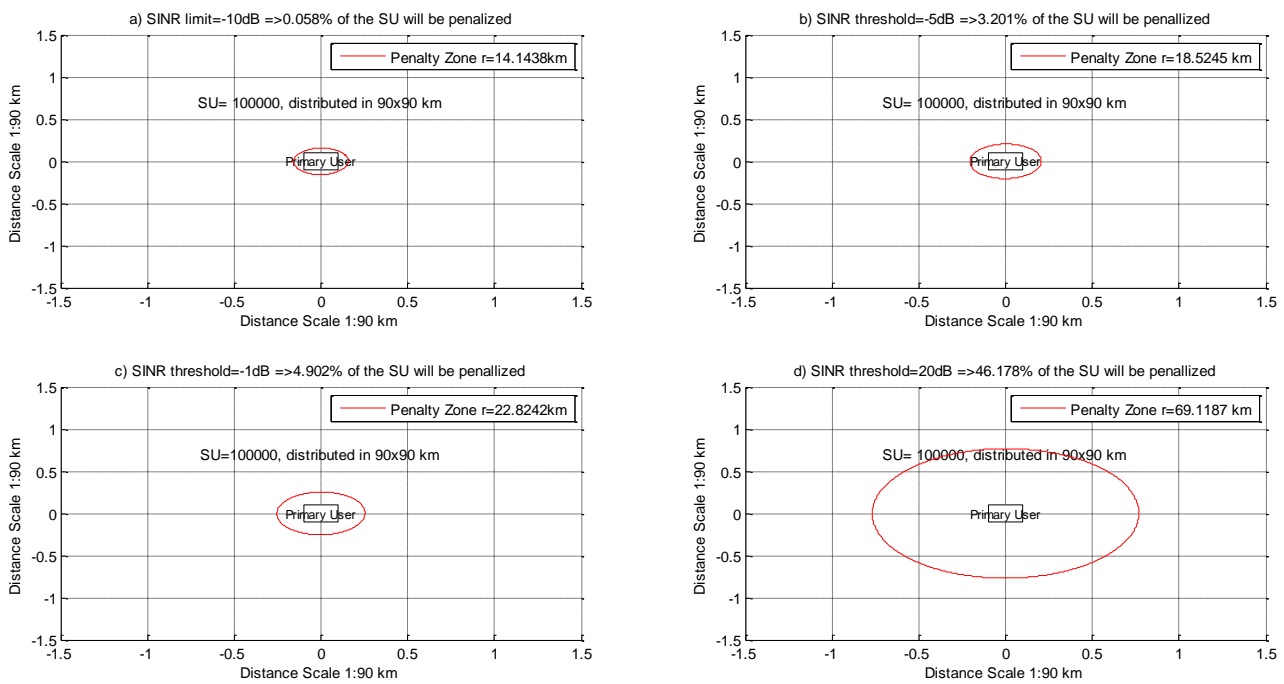

Figure 8: SINR vs penalty zone radius

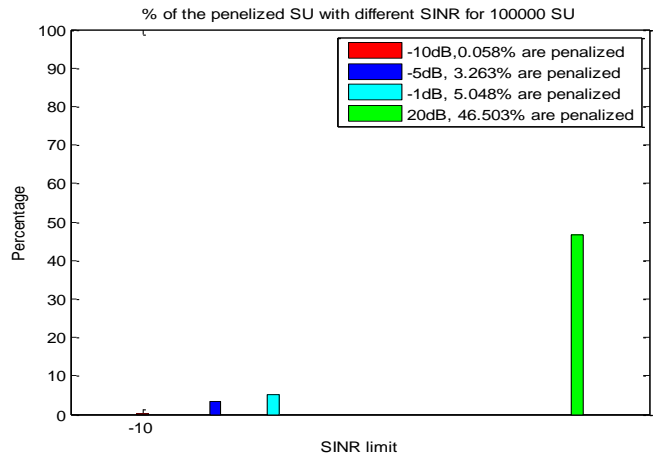

Figure 9: SINR limit vs percentage of penalized SU

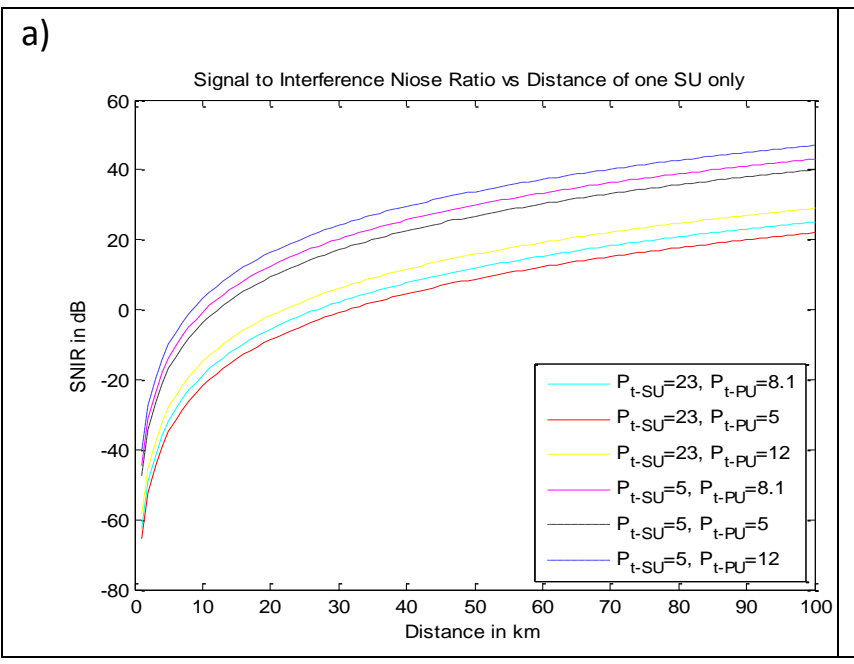

b)

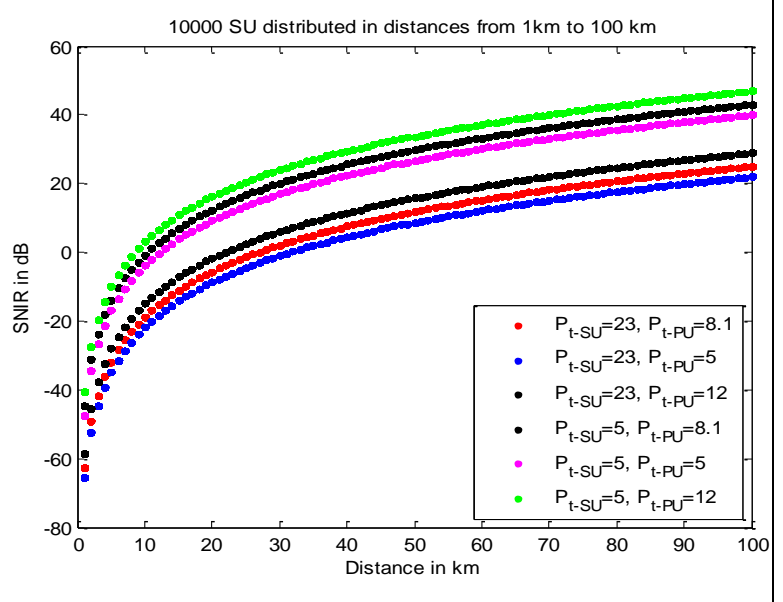

Figure10: SINR vs diastance 
Figure 10 shows the interference effect on the PU when varying the number of SU [1, 100000], PU EIRP is $[8.1,5,12] \mathrm{dB}$, and $\mathrm{SU}$ transmitted power is $[23,5] \mathrm{dBm}$. The results show not many differences on the SINR curve with changing the number of the SU. It shows also, when the SU transmit at lower power the SINR becomes better. Finally, these results show that no matter the number of the SU when the distance of the SU is less than $10 \mathrm{~km}$, the SINR decreases rapidly the closer the SU comes to the PU receiver.

Table 1 shows fluctuation in the SINR when the SUs distances and transmitted power are changed. We fixed the number of the secondary users to 100000 and the primary users transmitted power. This figure shows the effect of the SU on the SINR when they are $1 \mathrm{~km}, 2 \mathrm{~km}$, and $9 \mathrm{~km}$ far from the PU. It can be absorbed that at $9 \mathrm{~km}$ with $5 \mathrm{dBm}$ transmitted power the SINR is almost at $0 \mathrm{~dB}$.

\begin{tabular}{|c|c|c|}
\hline $\begin{array}{c}P_{S U-\text { transmit }}(\mathrm{dBm}) \\
23\end{array}$ & $\begin{array}{c}\text { SU distance } \\
\text { from } P U(\mathrm{~km})\end{array}$ & SINR $(\mathrm{dB})$ \\
\hline 5 & 1 & -60 \\
\hline 10 & 1 & -42 \\
\hline 23 & 1 & -45 \\
\hline 5 & 2 & -45 \\
\hline 10 & 2 & -28 \\
\hline 23 & 2 & -32 \\
\hline 5 & 9 & -18 \\
\hline 10 & 9 & 0 \\
\hline
\end{tabular}

Table 1: SINR vs distance and PU transmit power

Figure 11 shows the variation of the SU density around the PU versus the number of the penalized SUs. It shows the number of penalized SU when the SUs are dense in three different areas $[18 \mathrm{~km} \times 18 \mathrm{~km}$, $29.7 \mathrm{~km} \times 29.7 \mathrm{~km}, 45 \mathrm{~km} \times 45 \mathrm{~km}]$. The PU is simulated as the middle point of these areas. The transmitted power for the PU and the SU with the number of the SUs are fixed. The SINR is limited to $-10 \mathrm{~dB}$, so if the SU signal transmission power exceeds that limit the SU will be penalized. It can be seen that the more dens the SU around the PU the more SUs would be penalized. If the SU are not distributed in dens like the third case when the SU are distributed in $45 \mathrm{~km} \times 45 \mathrm{~km}$, only $9.661 \%$ of the SUs will be penalized. So, if the value for SU transmissions increases, users may find it valuable to risk higher interference penalty by transmitting closer to the PU's antenna. 

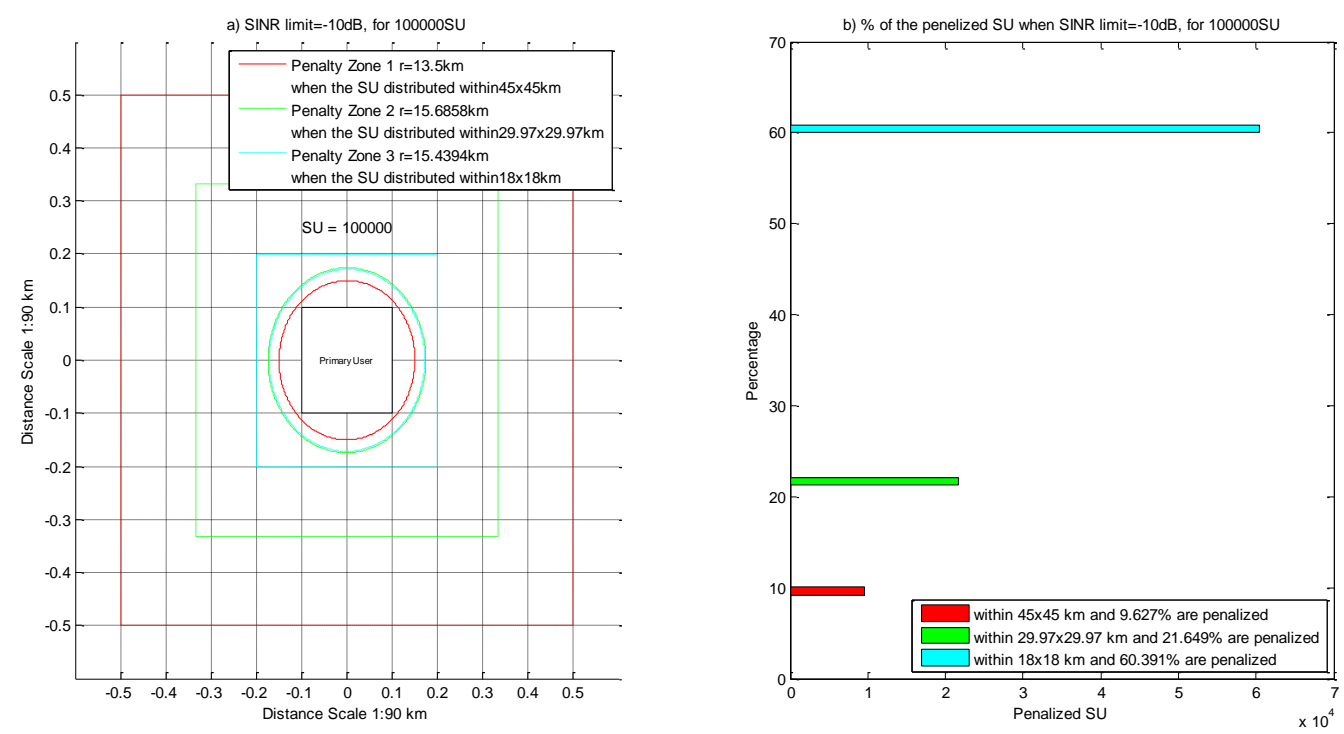

Figure 11: penalty vs Density

The SU can calculate the minimum penalty zone radius when the SINR limit is fixed to $-10 \mathrm{~dB}$ is $13.4 \mathrm{~km}$. We introduce a ratio value called Penalty Ratio $P R$ of the ex-post enforcement which is the ratio between the cost of the ex-post enforcement $C_{e p}$ and the radius of the SINR limit in $\mathrm{km}$ (equation a). The SU can calculate PR based on the best case scenario. Another equation can be derived from equation (a) to calculate the radius of the penalty zone each time that the enforcer decides to enhance the probability of detection or increase the changeable enforcement cost (equation b)

$$
\begin{aligned}
& \text { Penalty Ratio }=P R=\frac{C_{e p}}{R_{S I N R}} \text { with a unit of } \# S U \times \$ \text { per } k m--(a) \\
& R_{\text {penalty }}=\frac{C_{e p}}{P R}=\frac{N_{S U} \times \alpha(I+C)}{P R}----------(b)
\end{aligned}
$$

Equation(b) has three variables which are probability of detection, changeable enforcement cost and the penalty ratio $P R$. From equation (b) we can estimate that increasing either probability of detection or changeable enforcement cost will increase the radius of the penalty zone.

We will vary the penalty ratio $(P R)$ to see how the $\mathrm{PU}$ can increase the penalty zones and therefore gain more penalties from the SUs. The penalty values that we will use are $\left[P R, \frac{P R}{2}, \frac{P R}{3}, \frac{P R}{4}\right]$.

Figure 12-a shows the radius of the penalty zone is the same as the radius in figure 3-b but with slight difference in the number of penalized SUs. Figure $12-a, b$, and $c$ show the effect of the penalty ratio on the radius of the penalty zone when the penalty ratio changed to $P R, P R / 2$, and $P R / 3$. 

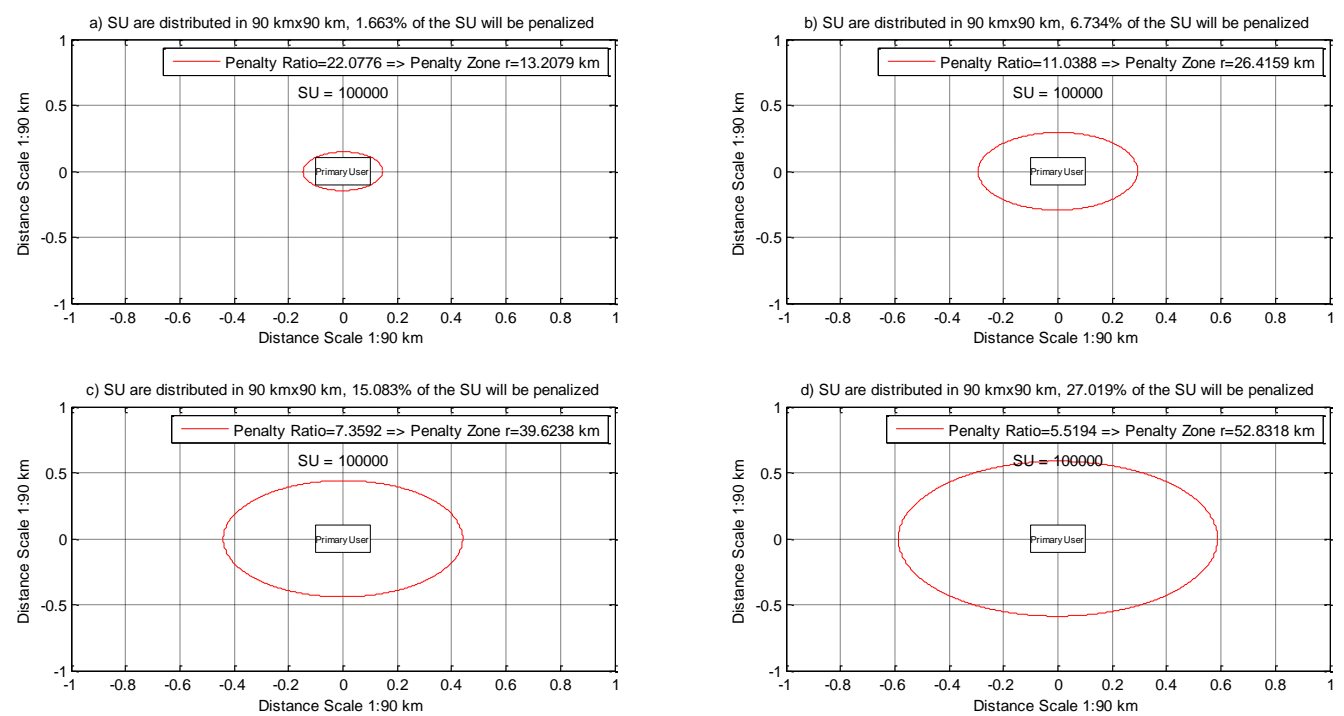

Figure 12: penalty zone radius variation 